\title{
Bone marrow necrosis at transformation of chronic granulocytic leukaemia treated with interferon
}

\author{
J R Kendra, S Pickens, K Singh
}

\begin{abstract}
A patient with chronic myeloid leukaemia was treated with interferon without using conventional cytotoxic agents. Bone marrow necrosis developed at the onset of blast transformation.

It is suggested that cytotoxic drugs should be given before treatment with interferon for chronic myeloid leukaemia. Cytotoxic drugs may also be needed to prevent rapid bone marrow growth once interferon has been withdrawn.
\end{abstract}

Bone marrow necrosis is a rare complication of a wide variety of disorders including leukaemia. ${ }^{1}$ Of the leukaemias with this complication, acute lymphoblastic is the most common. ${ }^{2}$ Bone marrow necrosis is rare in chronic myeloid leukaemia and only 11 cases have been reported..$^{3-9}$ Interferon (Intron-A) is a recent therapeutic addition in the treatment of chronic myeloid leukaemia and results show promise, with sustained cytogenetic remission in a small proportion of patients. ${ }^{10}$ Of the 11 previous case reports only one patient had received interferon, given in combination with busulphan.

\section{Case report}

A 58 year old caucasian man was referred for the investigation of dyspepsia. His spleen was palpable two finger breadths below the costal margin. Investigations showed a haemoglobin concentration of $13.4 \mathrm{~g} / \mathrm{dl}$, a white cell count of $58 \times 10^{9} / 1$ and a platelet count of $1697 \times 10^{9} / 1$. The differential cell count showed $1 \%$ blasts, $5 \%$ promyelocytes, $15 \%$ myelocytes, $6 \%$ metamyelocytes, $66 \%$ neutrophils, $5 \%$ lymphocytes and $2 \%$ basophils. The leucocyte alkaline phosphatase score was 20. The bone marrow was hypercellular with the appearances of the chronic phase of chronic myeloid leukaemia. Cytogenetic analysis showed a Philadelphia chromosome. Endoscopic examination showed superficial gastric erosions. Treatment for chronic myeloid leukaemia was started with interferon (IntronA) - 5 million units subcutaneously, daily, with Paracetamol to alleviate febrile reactions and muscle aches. General malaise and muscular stiffness prevented an increase in dose. Splenomegaly resolved after two months and by the fourth month the white cell count was $5.8 \times 10^{9} / 1$, platelet count $298 \times 10^{9} / 1$, and the haemoglobin had risen to $14.0 \mathrm{~g} / \mathrm{dl}$. The blood counts remained within the normal range for the next four months. At this time the patient went abroad for three weeks and the frequency of interferon was reduced to three times a week. During the holiday, the patient complained of fevers, stiff muscles, and lethargy, which impaired his mobility. When he returned to the United Kingdom he was admitted as an emergency and found to be febrile, with a temperature of $40^{\circ} \mathrm{C}$, and the spleen was three finger breadths palpable below the costal margin. The white cell count was $24 \times 10^{9} / 1$ with $2 \%$ blast cells, haemoglobin $11.2 \mathrm{~g} / \mathrm{dl}$, and platelets $364 \times 10^{9} / 1$. Interferon was discontinued and intravenous antibiotics given. The fever resolved within 24 hours. Antibiotics were discontinued on the fifth day and no growth was noted in blood cultures. During this time the serum creatinine rose from $118 \mu \mathrm{mol} / 1$ on admission to $531 \mu \mathrm{mol} / 1$. The white cell count was $38 \times 10^{9} / 1$ with $12 \%$ blast cells. A sternal marrow aspiration produced a dry tap; a sample from the posterior iliac crest was hypercellular with necrotic cells with ill defined margins in an amorphous background material. Bone marrow necrosis was diagnosed. Anuria developed and the patient was transferred for haemodialysis. The serum urate concentration was $0.9 \mathrm{mmol} / 1$. Haemodialysis was attempted but cardiac dysrhythmias prevented prolonged treatment. Four days later the white cell count rose to $70 \times 10^{9} / 1$ with $25 \%$ blast cells. Further dialysis was not attempted and the patient died five days later. Subsequent cytogenetic analysis detected an isochromosome 17, in addition to the Philadelphia chromosome. Immunological markers showed the origin of the blast cells to be nonlymphoid.

\section{Discussion}

Interferon has recently been licensed for the treatment of chronic myeloid leukaemia. In this condition, interferon may achieve normalisation of the blood counts, regression of splenomegaly, and in a small proportion of patients a sustained loss of the Philadelphia chromsome. ${ }^{10}$ The response is slow and may take six months to achieve haematological remission, and cytogenetic changes may require 12 months' treatment. We elected to treat our patient solely with interferon and without prior cytoreductive chemotherapy because the presenting white cell count was not excessive.

The pathogenesis of bone marrow necrosis is probably multifactorial and the complication 
may occur in a wide spectrum of diseases. It has been reported in chronic myeloid leukaemia during chronic phase and at blast transformation. As the marrow in chronic myeloid leukaemia is characteristically hypercellular, the rapid cell growth during clonal evolution to blast crisis could both infiltrate the vessel walls and compress the marrow blood supply, causing ischaemia of the marrow sinusoids.

Eleven cases of bone marrow necrosis and chronic myeloid leukaemia have been reported, but full documentation was not available for two reported by Brown, ${ }^{6}$ nor the three reported by Norgard et al. ${ }^{9}$ Survival can be prolonged if necrosis occurs during stable chronic phase, as noted by Brown. ${ }^{6}$ Bain reported a 20 month survival from the onset of necrosis and subsequent development of myelofibrosis. ${ }^{7}$ Macheta et al described a survival of 12 months from necrosis in chronic phase. $^{8}$

Three patients survived less than four weeks when necrosis occurred at the time of disease progression. ${ }^{458}$ However, Scudla et al ${ }^{3}$ reported a 14 week survival following bone marrow necrosis at blast crisis. This patient recovered focal areas of normal haemopoesis after unspecified chemotherapy.

Our patient did not receive cytoreductive chemotherapy but was treated with interferon alone. Although this resulted in the normalisation of the peripheral blood and regression of splenomegaly, it did not prevent blast crisis and the subsequent development of bone marrow necrosis. We wonder, therefore, if despite the improvement in the peripheral blood the bone marrow remained hypercellular so that when blast transformation occurred, there was already a large residual cell mass in situ, thus increasing the risk of bone marrow necrosis by compression.

Interferon also has an inhibitory effect on bone marrow cells. The reduction in interferon and the subsequent abrupt withdrawal may have allowed rapid expansion of bone marrow cells.

Cytoreductive chemotherapy should be given before treatment with interferon for chronic myeloid leukaemia. There may also be a need to cover the withdrawal of interferon with conventional chemotherapeutic agents to prevent rapid bone marrow growth.

We acknowledge the help of The Royal Preston Renal Unit and in particular, Dr A Coward and his staff and Mrs C Collins for typing the manuscript, and the staff Ward 3, Burnley Genera Hospital.

1 Maisel D, Lim JY, Pollock WJ, Yatani R, Liu PI. Bone marrow necrosis. An entity often overlooked. Ann Clin Lab Sci 1988;18:109-15.

2 Ching Hon PUI, Sanford S, Alexanda G. Bone marrow necrosis in children with malignant disease. Cancer 1985;56:1522.

3 Scudla V, Dusek J, Macak J, Zivna J, Myslivecek M, Indrak $\mathrm{K}$. Bone marrow necrosis in malignant diseases. A report on seven intravitally recognised cases. Neoplasma 1989; 36:603-10.

4 Lee $\mathrm{CH}$, Morris TCM. Bone marrow necrosis and extramedullary myeloid tumour necrosis in aggressive chronic myeloid leukaemia. Pathology 1979;11:551-6.

5 Dokal IS, Amos A, Bashey A, Goldman JM. Recurrent bone marrow necrosis and extramedullary deposits in philadelphia negative chronic myeloid leukaemia. Haematolica 1988;73:513-15.

6 Brown $\mathrm{CH}$. Bone marrow necrosis. fohns Hopkins Med 7 1972;131:189-203.

7 Bain B. Extensive bone marrow infarction followed by myelofibrosis in a patient with Philadelphia positive chronic myeloid leukaemia. F Clin Pathol 1980;33: 449-53.

8 Macheta AT, Cinkotai KI, Love EM, Geary CG, Yin JA. Bone marrow necrosis complicating chronic myeloid Bone marrow necrosis complicating chronic

9 Norgard NJ, Carpenter JT Jr, Conrad ME. Bone marrow necrosis and degeneration. Arch Intern Med necrosis and $1979 ; 139: 905-11$.

10 Talpaz M, Kantarjian H, McCredie K, Trujillo J, Keating $M$, Gutterman J. Haematologic remission and cytogenetic improvement induced by recombinant human Interferon Alph A in chronic myelogenous leukaemia. $N$ Engl f Med 1986;314:1065-9. 


\section{CORRECTIONS}

Our apologies to Dr A K Singh (Bone marrow necrosis at transformation of chronic granulocytic leukaemia treated with interferon) $\mathcal{f}$ Clin Pathol 1992;45:830-1. The first initial of his name was inadvertently omitted.

An error appeared in the article Modified latex agglutination test for antibodies to Toxoplasma gondii in eluates from Guthrie cards by Drs S P Parker and W D Cubitt $(\mathcal{F}$ Clin Pathol 1992;45:907-9). The legends to figures 2 and 3 were transposed.
Postgraduate course in gynecologic and obstetric pathology with clinical correlation

April 26-30, 1993

The Departments of Pathology, Massachusetts General Hospital and Brigham and Women's Hospital, Harvard Medical School, will present a postgraduate course in gynecologic and obstetric pathology under the direction of Drs Robert E Scully, Robert H Young, and Christopher P Crum, to be held at the Four Seasons Hotel, Boston.

This course is designed for pathologists and obstetrician-gynecologists at resident and practitioner levels. It will provide an in-depth review of gynecologic and obstetric pathology with emphasis on morphologic diagnostic features and clinicopathologic correlation including management. Special attention will be paid to recent advances and newly recognised entities. Instruction will be primarily by lecture, but will also include case presentations and discussion periods. Each participant will receive a comprehensive course syllabus.

The fee for the course is $\$ 695.00$ (residents and fellows $\$ 550.00$ ). For further information contact: Department of Continuing Education, Harvard Medical School, 25 Shattuck Street, Boston, MA 02115 (Telephone: 617432-1525).

\section{ACP Locum Bureau}

The Association of Clinical Pathologists runs a locum bureau for consultant pathologists.

Applicants with the MRCPath who would like to do locums and anyone requiring a locum should contact The General Secretary, 221 Preston Road, Brighton BN1 6SA. Tel (0273) 561188 Fax (0273) 541227.

\section{British Lymphoma Pathology Group Tutorial \\ 14-16 April 1993}

Chilworth Manor Residential Conference Centre, Chilworth, Southampton

\section{NOTICES}

\begin{tabular}{|c|} 
First International \& Eighth \\
European \\
Conference on Clinical \\
Hemorheology \\
July 5-8, 1993 \\
Vienna, Austria \\
Local organising committee: \\
A Hansel, KL Resch, T Saradeth, \\
Congress Secretariat, Dept Phys Med \\
Rehab, University of Vienna (AKH), \\
Währinger Gürtel 18-20, A-1097 \\
Vienna, Austria. Tel: +43/1/40400-4330 \\
Fax: +43/1/40400-5281
\end{tabular}

The following will be offered this Spring by the Ernest Witebsky Center for

Immunology, University at Buffalo, State University of New York:

\section{Recombinant DNA technology:} Methods and applications

Hands-on laboratory course

Monday, April 19, through Sunday, April 25, 1993

This seven-day course, presented in conjunction with Exon-Intron, Inc., provides both fundamental and advanced training in recombinant DNA technology. It is designed to provide and expand laboratory skills in molecular cloning techniques for individuals with a background in biological sciences but who have little or no knowledge of recombinant DNA techniques. Course registration fee of $\$ 1,200.00$ covers course materials, beverage breaks, and seven (7) days' luncheons. Registration will be limited to 24 persons.

\section{Methods of immunologic research and diagnosis}

An at-the-bench laboratory training programme

\section{Monday, May 10, through}

Thursday, May 20, 1993

This 10-day programme consists of daily practical laboratory exercises personally carried out by participants, accompanied by lectures, demonstrations and discussions. Exercises range from the basic techniques of antiserum preparation to advanced techniques of immunoassay. Open to individuals at the postdoctoral level, supervisory senior technologists and graduate students. Course registration of $\$ 700.00$ includes course materials and beverage breaks. Registration will be limited to 36 individuals.

\section{Latex particle immunoassays \\ Hands-on laboratory course}

Friday and Saturday, May 21-22, 1993

This course is designed to provide an overview of preparation, formulation, properties and applications of latex particles in medical laboratory diagnosis. Geared toward laboratory researchers and technicians, and in-vitro diagnostic manufacturers. Course registration fee of $\$ 295.00$ covers course materials, beverage breaks, and lunch on both days. Registration will be limited to 24 persons.

For further information on any of the above courses, contact Roger $K$ Cunningham, PhD, Director, The Ernest Witebsky Center for Immunology, 442 Sherman Hall, University at Buffalo, 3435 Main Street, Buffalo, New York 14214 Phone: 716/829-2901 Fax: 716/829-2158. Because class size is limited in all courses, we recommend registrations be submitted at least one month prior to respective starting dates for best possibility of acceptance. 